Article

\title{
Energy Saving Maximization of Balanced and Unbalanced Distribution Power Systems via Network Reconfiguration and Optimum Capacitor Allocation Using a Hybrid Metaheuristic Algorithm
}

\author{
Mohamed Abd-El-Hakeem Mohamed ${ }^{1}$, Ziad M. Ali ${ }^{2,3, *}$, Mahrous Ahmed ${ }^{4}\left(\mathbb{D}\right.$ and Saad F. Al-Gahtani ${ }^{5}$ (D) \\ 1 Faculty of Engineering, Electric Department, Al-Azhar University, Qena 83511, Egypt; \\ mohamedabdelhakem.38@azhar.edu.eg \\ 2 Electrical Engineering Department, College of Engineering at Wadi Addawaser, Prince Sattam bin \\ AbdulAziz University, Wadi Addawaser 11991, Saudi Arabia \\ 3 Electrical Engineering Department, Aswan faculty of Engineering, Aswan University, Aswan 81542, Egypt \\ 4 Department of Electrical Engineering, College of Engineering, Taif University, P.O. Box 11099, \\ Taif 21944, Saudi Arabia; m.elsamman@tu.edu.sa \\ 5 Electrical Engineering Department, Faculty of Engineering, King Khalid University, \\ Abha 61411, Saudi Arabia; saljbar@kku.edu.sa \\ * Correspondence: dr.ziad.elhalwany@aswu.edu.eg
}

Citation: Mohamed, M.A.-E.-H.; Ali, Z.M.; Ahmed, M.; Al-Gahtani, S.F. Energy Saving Maximization of Balanced and Unbalanced Distribution Power Systems via Network Reconfiguration and Optimum Capacitor Allocation Using a Hybrid Metaheuristic Algorithm. Energies 2021, 14, 3205. https:// doi.org/10.3390/en14113205

Academic Editor: Shady H.E. Abdel Aleem

Received: 26 April 2021

Accepted: 24 May 2021

Published: 30 May 2021

Publisher's Note: MDPI stays neutral with regard to jurisdictional claims in published maps and institutional affiliations.

Copyright: (c) 2021 by the authors. Licensee MDPI, Basel, Switzerland. This article is an open access article distributed under the terms and conditions of the Creative Commons Attribution (CC BY) license (https:// creativecommons.org/licenses/by/ $4.0 /)$.

\begin{abstract}
The main aim of this work was the maximization of the energy saving of balanced and unbalanced distribution power systems via system reconfiguration and the optimum capacitor's bank choice, which were estimated by using a new algorithm: modified Tabu search and Harper sphere search (MTS-HSSA). The results demonstrated that the proposed method is appropriate for energy saving and improving performance compared with other methods reported in the literature for IEEE 33-bus adopted systems, including large scale systems such as IEEE 119 and the IEEE 123 unbalanced distribution system. Moreover, it can be used for unbalanced distribution systems distributed generators (DGs). The results demonstrated that the proposed method (the optimal choice of shunt capacitor (SC) banks and the optimal reconfiguration via the proposed algorithm) is appropriate for energy saving compared with different strategies for energy saving, which included distributed generation (DG) at different cost levels.
\end{abstract}

Keywords: power losses; Tabu search; Harper sphere search; unbalanced system

\section{Introduction}

The maximization of energy saving of the distribution system is inspired by many strategies, such as a distribution system reconfiguration and optimum capacitor allocation [1-3] where allocation of shunt capacitors offered several benefits to the distribution power systems, not only maximizing energy saving but also improving the voltage profile. System reconfiguration can be used to ease the current feeders, therefore, improving the voltage profile of the system and maximizing energy saving. Several investigators have studied the problem of the reconfiguration and allocation of distribution and power systems and the problem of the sizing of shunt capacitors in distribution power systems separately. The analytical algorithms have been used for solving the problem of shunt capacitor allocation in $[4,5]$. Recently, heuristic algorithms have been widely used for solving this problem. The simulating annealing algorithm (SAA) [6], Tabu search (TS) [7], the genetic algorithm (GA) [8], cuckoo search algorithms $[9,10]$, particle swarm optimization (PSO) [11], the bee colony algorithm [12], the ant colony algorithm [13], and the firefly algorithm [14] were presented to solve the problem of shunt capacitor allocation placement. The firefly algorithm was presented in [15] for solving the same problem in a radial distribution system via loss of the sensitivity factor. Improved harmony algorithms (IHA) 
were introduced in [16,17] with the newest objective function. Study [18] showed the effectiveness of the hyper-spherical search algorithm for the optimum sizing and allocation of capacitors compared to the other investigations mentioned above.

Civanlar [19] estimated a switching exchange method, in which the loss reduction was based on the switching option. A reconfiguration problem was solved in paper [20] Based on a linear programming network structure, a geometrical solution was used to find the best reconfiguration in [21]. A simulated annealing algorithm has been used for Distribution Power Systems Reconfiguration (DPSR) [22], and it has also been used for DPSR with an optimum discrete algorithm for estimation of the shunt capacitors [23]. A modified simulated annealing algorithm has been used for DPSR [24]. A genetic algorithm has been used for DPSR [25]. Evolutionary programming has also been used to solve the DPSR problem [26]. Studies $[27,28]$ presented improved and modified Tabu search algorithms, respectively, for loss-minimization reconfiguration of large-scale distributed systems. The improved selective binary particle swarm optimization (IS-BPSO) [29] algorithm has been used to solve the problem of DPSR. In [30], the optimal reconfiguration of the electric distribution network was done via the binary particle swarm gravity search algorithm. Study [31] demonstrated the efficiency of the Tabu search algorithm, where it was used to find the best solution in each neighborhood, penalizing the rules that were already applied in the iteration.

Farahani [32] applied two approaches via GA. The harmony search algorithm [33] was used for solving this problem but it did not consider the cost of the capacitor. Additionally, in [34], the improved binary particle swarm optimization (IBPSO) method was used for the same task to reduce power loss. In [35], a modified flower pollination algorithm (MFPA) was used for cost minimization by using two approaches (reconfiguration and capacitor allocation), but it gave results closed to the system with reconfiguration only at the large power system.

The main objective of study [36] was the minimization of total power losses by using two approaches (reconfiguration and capacitor allocation) via the hybrid big bang big crunch algorithm, which is an efficient algorithm for unbalanced systems; but, it did not consider the cost calculations.

In [37], a modified algorithm based on biogeography optimization was used to find the optimal reconfiguration and capacitor allocation, but it did not consider the cost of the capacitor. Additionally, it was not applied to a large distribution power system.

Most of the previous methodologies are concerned with balanced distribution power systems. In [38], the salp swarm algorithm (SSA) was used for solving the optimization of the reconfiguration problem. In [39], the two-stage firefly algorithm was used for the optimization of the reconfiguration problem. In [40], backward/forward sweep and direct load flow methods were used for optimal switchable capacitor allocation for different distribution systems. In [41], the P-PSO algorithm was used to find the optimal reconfiguration and capacitor. In [42], stochastic fractal search (SFS) was used to solve the optimization of the reconfiguration problem. In [43], the optimal choice of capacitor banks in the distribution system was executed by using the artificial electric field algorithm. Additionally, the same problem was solved by using the modified best-guided artificial bee colony (MGABC) algorithm in [44].

In [45], the Pareto-optimization algorithm was applied for solved reconfiguration problem only in unbalanced distribution system with the presence of distributed generators (DGs). In [46], the GA and the branches exchange method were used for unbalanced systems. Monte Carlo simulation (MCS) was carried out in [47].

Distribution network enhancement using network reconfiguration and DG integration via different algorithms such as the dataset approach and the water cycle algorithm [47], the PSO-DA optimization techniques [48], and the stochastic fractal search algorithm [49].

Other strategies included distribution network enhancement via shunt capacitors and DG integration using different algorithm such as constriction factor particle swarm optimization [50], the hybrid local search-genetic algorithm [51], and the Dragonfly algo- 
rithm [52], as well as distribution network enhancement via network reconfiguration and DG integration using shunt capacitors via different algorithms such as the thief and police algorithm [53], the harmony search algorithm (HSA), and the particle artificial bee colony algorithm (PABC) [54].

A majority of the studies in this region paid attention to capacitor allocation only or the reconfiguration of the network only of balanced and unbalanced systems. There are a few studies that applied two approaches simultaneously for reducing the energy costs of balanced systems, but there is no study that applied two approaches simultaneously for reducing the energy costs of balanced and unbalanced distribution power systems. So, we paid attention to use a novel meta-heuristic algorithm (HSSA-MTS) for maximization of energy saving in balanced and unbalanced distribution system via two approaches.

This study used the improved Tabu search algorithm and the Harper sphere search algorithm (MTS-HSSA) to maximize energy saving of the distribution power system. Where the literature review shows the effectiveness of HSSA for optimum sizing and allocation of capacitor banks, the improved Tabu search algorithm, on the other hand, was used to find the best solution to the system reconfiguration problem. So, MTS and HSSA were used for optimal allocations, the sizing of shunt capacitors, and feeder reconfiguration of the distribution system simultaneously. Additionally, the proposed algorithm was used for maximization of energy saving of an unbalanced distribution system.

The main contributions of the study could be summarized as follows:

- A novel meta-heuristic algorithm (HSSA-MTS) was investigated to obtain the optimal solution of the energy-saving problem via the optimal choice of SC banks and the optimal reconfiguration, which ensures convergence. The proposed algorithm collects the advantages of MTS and HSSA, e.g., it can solve a mixed integer programming problem for the system reconfiguration. Moreover, the proposed algorithm restricts the trial solution by checking the system to be radial during the reconfiguration process, and the power loss index (PLI) was used to provide a good initial solution for the optimum allocation of capacitors. High convergence probability was achieved because of the use of the hyper-sphere space idea, which closely restricts the searching space.

- The other novelty of this work is that, unlike previous works about energy saving for unbalanced distribution systems, which were only concerned with the solved reconfiguration problem, the proposed algorithm was used for maximization of energy saving of the unbalanced distribution system via the optimal choice of SC banks and the optimal reconfiguration. Additionally, it was used for unbalanced distribution systems with the presence of distributed generators (DGs).

- The results demonstrate that the proposed method is appropriate for energy saving and improving performance compared with other methods reported in the literature for IEEE 33-bus adopted systems, including large scale systems such as IEEE 119 and the IEEE 123 unbalanced distribution system. Additionally, the results demonstrate that the proposed method (optimal choice of SC banks and optimal reconfiguration via the proposed algorithm) is appropriate for energy saving compared with different strategies for energy saving that included distributed generation (DG) at different cost levels.

The article is organized as follows. Section 1 provides an overview of the approaches and methodologies of maximization of energy saving of the distribution system. Section 2 describes the problem formulation and a new algorithm: modified Tabu search and Harper sphere search. In Section 3, the proposed method is applied and the obtained results are discussed. Section 4 estimates the conclusions of the study.

\section{Materials and Methods}

The proposed route, which is described in this section, was used for the maximization of energy saving in different distribution power systems via the system reconfiguration and optimum capacitor's bank choice. The balanced distribution power systems had different sizes such as IEEE 33 and a large number of buses in IEEE 119. The proposed route can be 
applied to unbalanced distribution power systems such as the IEEE 123 distribution power system. In the next section, these systems are modified based on the proposed algorithm to ensure its effectiveness.

\subsection{Problem Description}

\subsubsection{Objective Function Definition}

The main objective of optimal allocations, sizing of shunt capacitors, and feeder reconfiguration of the distribution system is to minimize the annual energy losses, which is the objective function. This is formulated in Equation (1) [17,41].

$$
J=\min \left[K_{p} C_{\text {losses }}\left(X_{c} \cdot X_{r}\right)+D\left(K_{I} \sum_{i=1}^{N_{C b}} i+K_{c} \sum_{i=1}^{N_{c b}} x_{c, i}\right)+K_{o} N_{c b}\right]
$$

where

$X_{r}=\left[x_{1} x_{2} \ldots x_{i} \ldots x_{n}\right]$

$x_{i}$ : The status of switch no $\mathrm{i}$

$X_{c}=\left[Q_{\mathrm{c} 1} Q_{\mathrm{c} 2} Q_{\mathrm{c} 3} \ldots Q_{n \mathrm{cb}}\right]$

$K_{\mathrm{p}}$ : Total costs $/ \mathrm{kWh}$

$K_{\mathrm{c}}$ : Total costs/KVAR

$K_{I}$ : Capital installation costs

$K_{o}$ : Operational costs

\subsubsection{Constraints}

To obtain the optimal solution, the following conditions should be achieved:

1. Real power and reactive power constraints. The power flows of the slack bus must be balanced with the generated power and the load demand.

$$
\begin{gathered}
P_{\text {slack }}=\sum_{i=1}^{N} P_{l d, i}+\sum_{j=1}^{N_{L}} P_{\text {losses }, i} \\
Q_{\text {slack }}=\sum_{i=1}^{N} Q_{l d, i}+\sum_{i=1}^{N_{L}} Q_{\text {losses }, i}-\sum_{i=1}^{N_{c b}} Q_{c, i}
\end{gathered}
$$

2. Injection reactive power constraint.

Constraint (4) states the boundary condition of the reactive power limit:

$$
Q_{c, \min } \leq Q_{c, \mathrm{i}} \leq Q_{c, \max }
$$

3. Voltage magnitude constraints.

$$
V_{\min } \leq V_{i} \leq V_{\max } \quad \forall i \in N
$$

where the voltage limits are $(0.9,1.05)$.

4. Current of lines constraints.

$$
I_{l, \min } \leq I_{l, i} \leq I_{l, \max } \quad \forall i \in N_{L}
$$

\subsection{MTS-HSSA Algorithm for Optimum Operation of Distribution System}

The Tabu search algorithm was used to find the best solution for system reconfiguration problems [28], and this problem was very confident with this method. The standard Tabu search algorithm is described in Appendix A. HSSA, which is described in Appendix $B$, achieved the best solutions for optimal allocations and the sizing of shunt capacitors $(X c)$ in [18]. This section explains a compound algorithm between three methods, which were the power loss index, the HSSA algorithm, and the Tabu algorithm, to find the 
best values of $(X r)$ and $(X c)$. The complete flow chart of the proposed algorithm is shown in Figure 1. Also, the following steps describe the proposed algorithm to find $(X r)$ and $(X c)$, which minimize the cost function in Equation (1)

Step 1: Estimate the set of the distribution power system configuration $\Omega$ [28].

$$
\Omega=\Omega_{1} \cup \Omega_{2}
$$

where

$\Omega_{1}$ : set of the sectionalizing switches.

$\Omega_{2}$ : set of the switches of tie lines.

Step 2: Input initial values of Tabu parameters and initial solutions of $X_{\mathrm{r}}$.

Step 3: Choose a tie line $(T)$ for the exchange operation.

Step 4: Execute a branch exchange between a tie line $T$ and a branch $P$.

Step 5: Determine the incidence matrix $(A)$ [28].

$A i j=1$ if branch no $(i)$ is directed-away from the bus $(j)$.

$A i j=-1$ if branch no $(i)$ is directed-away to bus no (j).

$A i j=0$ if branch no (i) is not incident to bus no $(j)$.

Step 6: Check if the system is still radial after step 4 as follows:

$\|A\|=1$ or -1 (the system is radial).

Go to the next step, or else go to step 3.

Step 7: Calculate the cost function for the current configuration using a power flow study via the Newton-Raphson method.

Step 8: Move the current solution to the best one in the candidate neighborhood while meeting the Tabu restriction and update the Tabu list.

Step 9: Go to step 10 if the stop criterion is satisfied. Otherwise, return to step 3.

Step 10: Restore the best reconfiguration of the distribution power system.

Step 11: Calculate the power loss index for all buses via the next equation [17]:

$$
P L I(i)=\frac{P(i)-P_{\min }}{P_{\max }-P_{\min }}
$$

$P_{\text {Losses, }}, \mathrm{i}:$ power losses of line i.

$P_{\text {max }}:$ maximum real power reduction through all buses.

$P_{\text {min }}$ : minimum real power reduction through all busses.

Step 12: Estimate the initial location of the capacitors corresponding to the buses with the highest PLI values and initialize particle values via step 11.

Step 13: Initial set of solutions (particles) are generated randomly $X_{c i} \in\left(X_{c i, \min }: X_{c i, \max }\right)$ and Nsc hyper-sphere centers (HSCs) are selected corresponding to the smallest values of the objective function [18].

The initial set of solutions is generated randomly in the specified band. For each solution (particle) and $\mathrm{N}$-dimensional problem, each particle is $1{ }^{*} \mathrm{~N}$ vector, $\left(p_{1}, p_{2}, \ldots, p_{N}\right)$. The following items should be defined:

Qmin and Qmax.

Number of particles.

Number of HSCs. (NSC $=0.1$ or $1 / 15$ of number of Particles.)

Max number of iterations.

Searching radius.

Two parameters of the dummy process, which are zeta and the number of dummy particles/iteration.

Step 14: Each particle is represented by using spherical coordinates $(r, \theta$, and $\varphi)$, which are shown in Figure A2 (Appendix B). 
Npop particles are reproduced, and the stay particles are allocated surrounded by HSCs via the -sphere centers dominance [18]. The particles were divided proportionally so the normalized dominant sphere center $\left(D_{s c}\right)$ is defended as follows:

$$
D_{s c}=\left|\frac{O F D_{s c, i}}{\sum_{i=1}^{N_{s c}} O F D_{s c, i}}\right|
$$

where

OFD $D_{s c}$ : objective function difference, which is:

$$
O F D_{s c, i}=f_{s c}\left(X_{i}\right)-\max \left\{f_{s c}\left(X_{i}\right)\right\}
$$

The number of particles among hyper-spheres is calculated according to Equation (11).

$$
n=\operatorname{round}\left\{D_{s c} \times\left(N_{\text {pop }}-N_{s c}\right)\right\}
$$

where

$N_{\text {pop }}$ is the number of the initial population.

The initial number of particles is chosen randomly by each sphere center from the remaining particles.

Step 15: The position of particles is changed via probability $\operatorname{Pr}_{\text {angle }}$ and $r \in\left(r_{\min }, \mathrm{r}_{\max }\right)$. Figure A2 shows the searching region of the particle (dashed-space)

The procedure of searching is achieved through moving in a $(r, \theta, \varphi)$ dimension, as shown in Figure A2. $\theta$ and $\varphi$ varied uniformly between $(0,2 \pi)$ and reproduced a new movement of the particle. These angles $\left(\theta\right.$ and $\varphi$ ) varied with the probability $P r_{\text {angle }}$ for each iteration.

$$
r_{\max }=\sum_{i=1}^{N}\left(P_{i, \text { center }}-P_{i, \text { particle }}\right)^{2}
$$

Step 16: The sphere centers with the largest value of the objective function should be varied. The dummy particle is shown in Figure A3 (Appendix B). It should have been allocated to a new sphere center via a set of objective functions (SOF). Dummy particles re selected to look for the new sphere centers via the assignment probability (AP) of the sphere centers.

The AP is given by the next Equation:

$$
A P=\left|\frac{D S O F}{\sum_{i=1}^{N_{S C} D S O F_{i}}}\right|
$$

where

$$
\begin{aligned}
D S O F & =S O F-\max _{\text {group }}\{S O F \text { groups }\} \\
S O F & =f_{s c}+\gamma \text { mean }\left(f_{\text {particles of } S C}\right)
\end{aligned}
$$

Step 17: The particles $\left(\mathrm{N}_{\text {newpar }}\right)$ with the worst are eliminated. Such particles are $\mathrm{r}$ placed by a new group of particles with the same number $\mathrm{N}_{\text {newpar }}$ described in step 14.

Step 18: Go to step 19 if the stop criterion is satisfied. Otherwise, return to step 14. Step 19: End. 


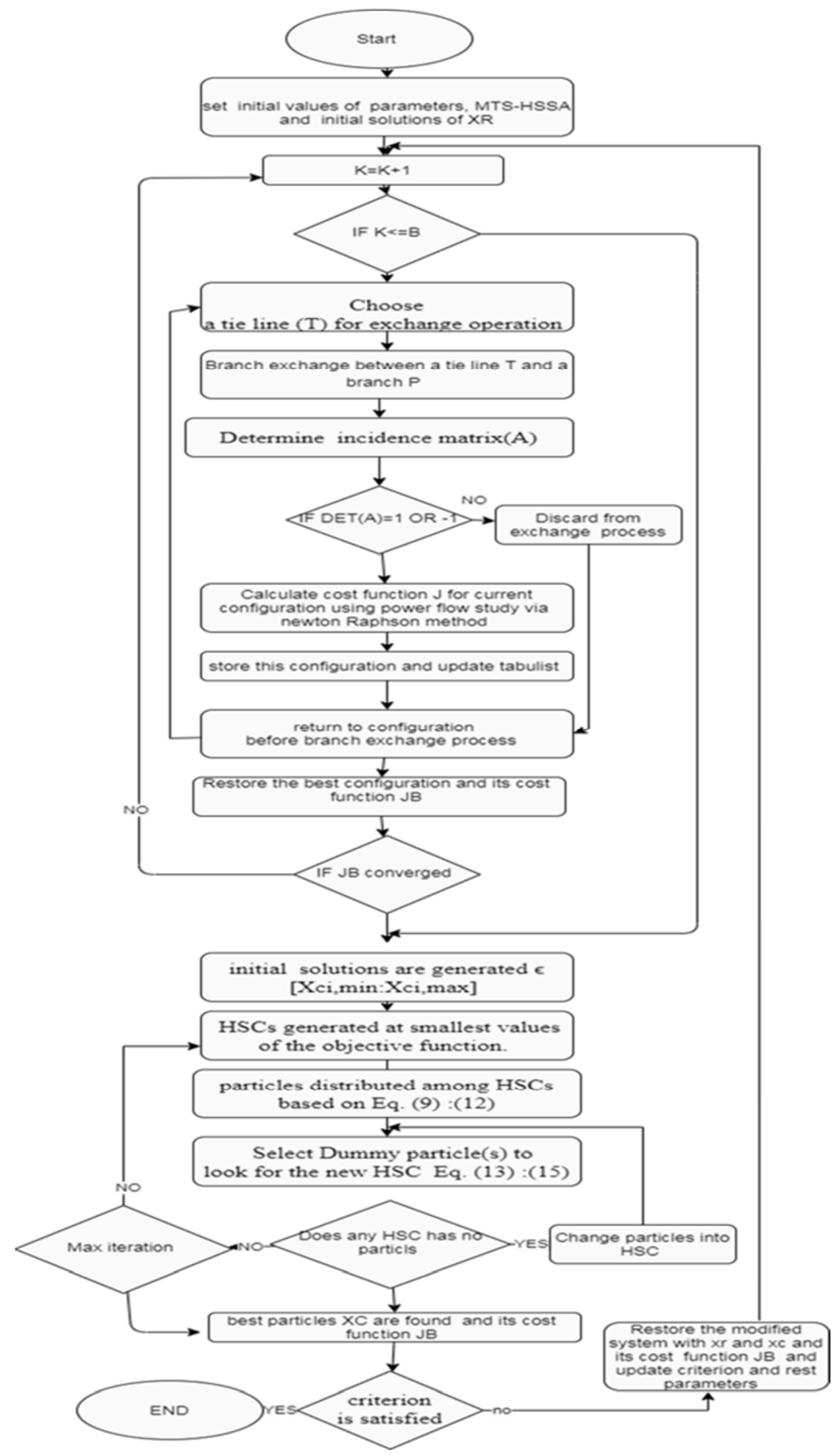

Figure 1. MTS-HSSA flow chart. 


\section{Results and Discussion}

The proposed route was applied to one of the distribution power systems with a large number of buses to ensure its effectiveness. This system was a 119 IEEE distribution power system and its data is contained in [27]. There is a scarcity of references that have used a large distribution system for optimal reconfiguration and capacitor allocation simultaneously, so model 33 IEEE [55] had to be used to conduct the comparison process.

The Newton-Raphson method was used to study the flow of power and to calculate the total lost power in the lines of 33 IEEE and 119 IEEE systems; the base data is tabulated in Table 1

Table 1. The base data of the systems under study.

\begin{tabular}{ccc}
\hline Items & IEEE 33 Base Values & IEEE 119 Base Values \\
\hline Total losses $(\mathrm{kW})$ & 202.66 & 1294.35 \\
\hline Minimum voltage & 0.913 & 0.8688 \\
\hline Annual cost $($ \$ / year $)$ & 112,500 & 680,310 \\
\hline
\end{tabular}

The cost calculations can be recalculated based on Equation (1) and the data of Tables 1 and 2. The proposed method, which is explained in detail in the previous section of this article, was applied. Its outputs are included in Table 3 as follows:

1. The reconfiguration only of IEEE119 and IEEE 33 power distributions systems;

2. The optimal places and values of capacitors only of IEEE119 and IEEE 33 power distributions systems;

3. The reconfiguration and optimal places and values of capacitors simultaneously of the IEEE119 and IEEE 33 power distributions systems.

Table 2. The parameters for recalculation of the cost [18].

\begin{tabular}{cc}
\hline Parameter & Values \\
\hline$K_{p}(\$ / k W h)$ & 0.06 \\
\hline$T(H)$ & 0.8760 \\
\hline$D$ & 0.2 \\
\hline$K_{c}(\$ /$ KVAR $)$ & 25 \\
\hline$K_{o}(\$$ year/location $)$ & 300 \\
\hline$K_{i}(\$)$ & 1600
\end{tabular}

The IEEE 33 system consisted of 37 switches; switches from 1 to 32 are normally closed, and switches from 33 to 37 are open. This system had a $V_{\text {nominal }}=12.66 \mathrm{kV}$ with the $V_{\min }=0.9 \mathrm{pu}$ and the $V_{\max }=1.0 \mathrm{pu}$ The best open switches and optimal capacitor allocations for case 1, case 2, and case 3 to minimizes the objective in Equation (1) are given in Table 3. The voltage profile and the VSI profile were improved for the 33-bus at different cases via the proposed algorithm, as shown in Figure 2. Additionally, the maximum voltage deviation and voltage deviation index were reduced. Power losses and energy costs were reduced for three modified IEEE 33 systems SC only, reconfiguration only, and SC with reconfiguration) via the proposed algorithm. It was noticed that the performance of the IEEE 33 system with reconfiguration via the MTS-HSSA algorithm was better than its performance with the optimal choice of capacitors. The IEEE 33 system with reconfiguration and optimal choice of capacitors. 
Table 3. The outputs of the proposed method.

\begin{tabular}{cccc}
\hline Items & $\begin{array}{c}\text { Reconfiguration } \\
\text { Only }\end{array}$ & $\begin{array}{c}\text { Capacitor } \\
\text { Allocation Only }\end{array}$ & $\begin{array}{c}\text { Reconfiguration and } \\
\text { Capacitor Location }\end{array}$ \\
\hline $\begin{array}{c}\text { Location and size of the } \\
\text { capacitor }\end{array}$ & & $30-850$ & 30650 \\
(IEEE 33) & & $14-300$ & 25350 \\
Tie lines (open) & 89 & $25-200$ & 31200 \\
(IEEE 33) & 1732 & - & 89 \\
& & 1161450 & 1732 \\
& & 522150 & 1161350 \\
Location and size of the & & 831050 & 52210 \\
capacitor & & 741150 & 831100 \\
(IEEE 119) & & 101800 & 731350 \\
& & 79500 & 112900 \\
& 2526 & 113850 & 77500 \\
& 3536 & & 114350 \\
Tie lines (open) & 4344 & & 251650 \\
(IEEE 119) & 4445 & & 3536 \\
& 3435 & & 4344 \\
& & & 4445 \\
& & & 3435 \\
\hline
\end{tabular}

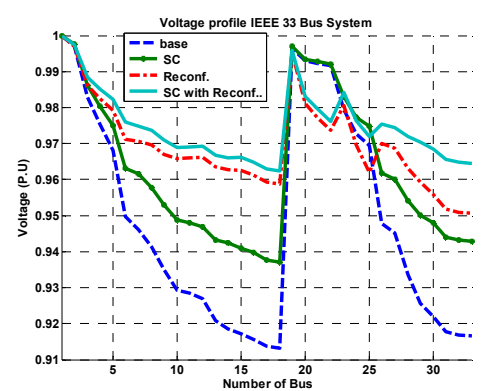

(a)

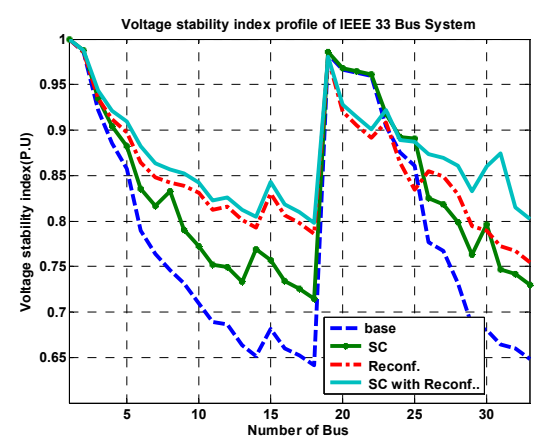

(c)

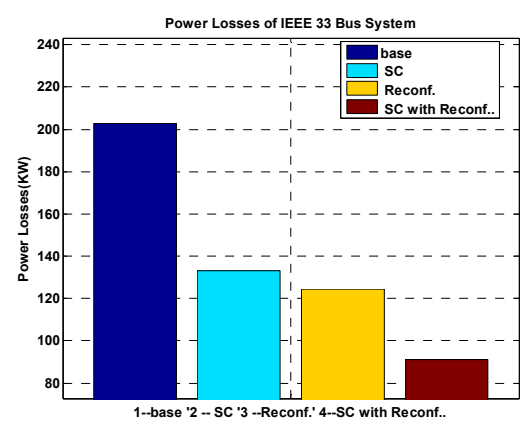

(e)

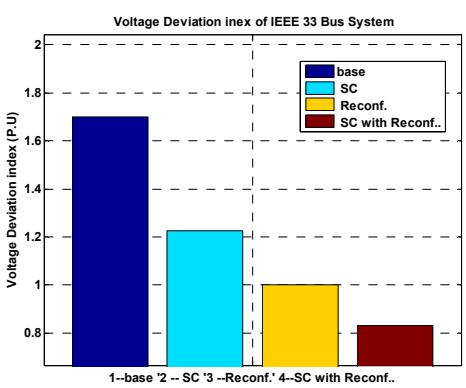

(b)

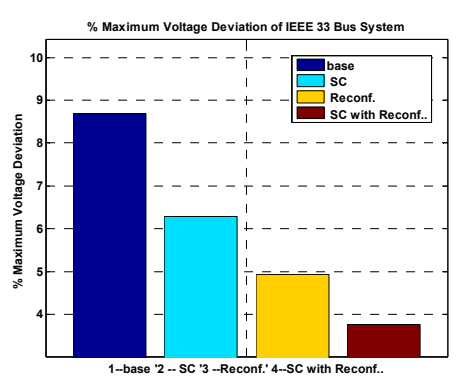

(d)

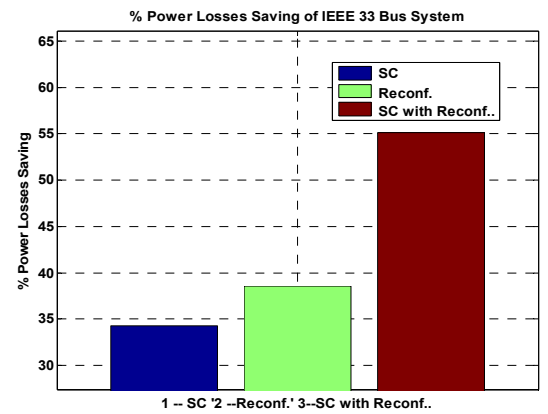

(f)

Figure 2. Cont. 


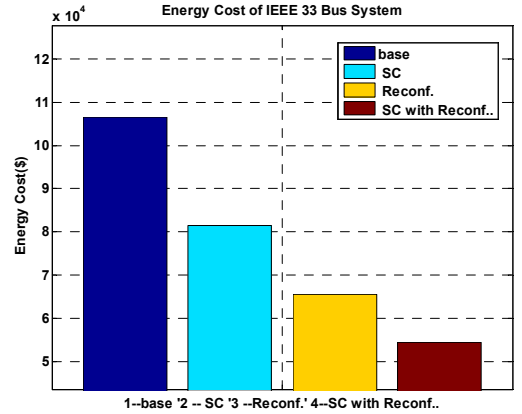

$(\mathrm{g})$

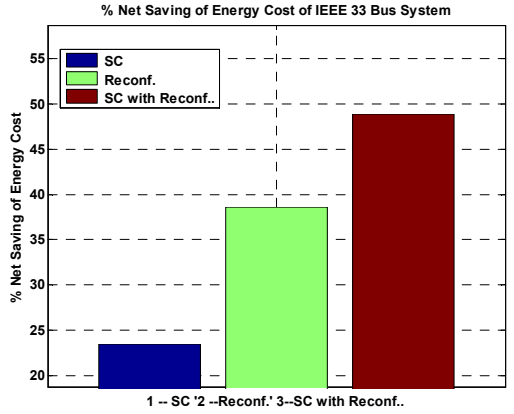

(h)

Figure 2. Performance of the 33-node test system with capacitor allocation only; the reconfiguration of the network only and the two approaches via the proposed algorithm: (a) Values of voltages at all buses; (b) values at different cases of the voltage deviation index; (c) values of voltage stability; (d) percentage of maximum voltage deviation; (e) power losses; (f) percentage of power losses saving; (g) energy cost; (h) percentage of energy cost-saving.

The performance of the distribution power system can be estimated by using the voltage deviation (VD) index [56,57], which was calculated by using Equation (16).

$$
V_{D}=\sum_{i=1}^{N}\left|1-V_{i}\right|
$$

The voltage stability index (VSI) was used for monitoring the stability of the distribution power system and detecting the weak buses. It can be calculated by using Equation (17).

$$
V S I=V_{i}^{4}-4\left(P_{i} X_{e f f i}+Q_{i} R_{e f f i}\right) V_{i}^{2}-4\left(P_{i} X_{e f f i}-Q_{i} R_{e f f i}\right)^{2}
$$

via the MTS-HSSA algorithm gave the best performance compared with the other cases.

The modified systems were compared with previous works at six cases, which are:

Case 1: IEEE 33 system with reconfiguration only, as shown in Table 4.

Case 2: IEEE 33 system with capacitor allocation only, as shown in Table 5.

Case 3: IEEE 33 system with reconfiguration and capacitor allocation, as shown in Table 6. Case 4: IEEE 119 system with reconfiguration only, as shown in Table 7.

Case 5: IEEE 119 system with capacitor allocation only, as shown in Table 8.

Case 6: IEEE 119 system with reconfiguration and capacitors allocation, as shown in Table 9.

\begin{tabular}{|c|c|c|c|c|c|c|}
\hline Items & $\begin{array}{l}\text { MFPA [35] } \\
\quad(2017)\end{array}$ & $\begin{array}{c}\text { BPSOGSA [30] } \\
(2018)\end{array}$ & $\begin{array}{c}\text { Two Stage FA } \\
\text { [39] } \\
(2020)\end{array}$ & $\begin{array}{l}\text { MBBO [37] } \\
\quad(2020)\end{array}$ & $\begin{array}{c}\text { Metaheuristic } \\
\text { Optimization [56] } \\
\text { (2021) }\end{array}$ & $\begin{array}{c}\text { Proposed } \\
\text { Method }\end{array}$ \\
\hline Power losses $(\mathrm{kW})$ & 139.54 & 138.62 & 139.98 & 129.9 & 138.93 & 124.49 \\
\hline$\%$ reduction in power losses & $31.15 \%$ & $31.50 \%$ & $30.93 \%$ & $35.90 \%$ & $33.35 \%$ & $38.57 \%$ \\
\hline $\mathrm{V}_{\min }(\mathrm{PU})$ & 0.937 & 0.942 & 0.943 & 0.95 & 0.9423 & 0.9506 \\
\hline Cost (\$/year) & 73,342 & 72,863 & 73,573 & 68,278 & 73,318 & 65,433 \\
\hline Savings (\$/year) & 33,176 & 33,655 & 32,945 & 38,240 & 24,195 & 41,085 \\
\hline \% savings & $31.15 \%$ & $31.59 \%$ & $30.93 \%$ & $35.90 \%$ & $33.35 \%$ & $38.57 \%$ \\
\hline
\end{tabular}

Table 4. IEEE 33 system with reconfiguration only. 
Table 5. IEEE 33 system with capacitor allocation only.

\begin{tabular}{cccccc}
\hline Items & $\begin{array}{c}\text { PPSO [41] } \\
\mathbf{( 2 0 1 6 )}\end{array}$ & $\begin{array}{c}\text { MFPA [35] } \\
\mathbf{( 2 0 1 7 )}\end{array}$ & $\begin{array}{c}\text { SCA [40] } \\
\mathbf{( 2 0 2 0 )}\end{array}$ & $\begin{array}{c}\text { PSO [40] } \\
\mathbf{( 2 0 2 0 )}\end{array}$ & $\begin{array}{c}\text { Proposed } \\
\text { Method }\end{array}$ \\
\hline Power losses $(\mathrm{kW})$ & 137.07 & 139.54 & 138.85 & 139.26 & 133.2 \\
\% reduction in power losses & $32.36 \%$ & $31.14 \%$ & $31.48 \%$ & $31.28 \%$ & $34.27 \%$ \\
V $_{\text {min }}($ PU) & 0.947 & 0.922 & 0.931 & 0.933 & 0.937 \\
Injected reactive power & 1950 & 1750 & 1863 & 2087 & 1550 \\
(KVAR) & 84,895 & 83,952 & 84,153 & 85,492 & 80,241 \\
Cost (\$/year) & 21,623 & 22,566 & 22,365 & 21,027 & 26,277 \\
\hline Savings (\$/year) & & & &
\end{tabular}

Table 6. IEEE 33 system with reconfiguration and capacitor allocation.

\begin{tabular}{|c|c|c|c|c|c|}
\hline Items & $\begin{array}{c}\text { PPSO } \\
\text { scen.6 [41] } \\
(2016)\end{array}$ & $\begin{array}{c}\text { MFPA [35] } \\
\text { (2017) }\end{array}$ & $\begin{array}{l}\text { IBPSO [34] } \\
(2014)\end{array}$ & $\begin{array}{l}\text { MBBO [37] } \\
\quad(2020)\end{array}$ & $\begin{array}{c}\text { Proposed } \\
\text { Method }\end{array}$ \\
\hline Power losses $(\mathrm{kW})$ & 93.39 & 101.77 & 93.06 & 110.61 & 91.01 \\
\hline$\%$ reduction in power losses & $53.91 \%$ & $49.78 \%$ & $54.08 \%$ & $45.41 \%$ & $55.09 \%$ \\
\hline $\mathrm{V}_{\min }(\mathrm{PU})$ & 0.96 & 0.954 & 0.962 & 0.95 & 0.962 \\
\hline $\begin{array}{l}\text { Injected reactive power } \\
\text { (KVAR) }\end{array}$ & 2100 & 950 & 2100 & 900 & 1200 \\
\hline Cost $(\$ /$ year $)$ & 62,686 & 60,100 & 62,512 & 64,500 & 55,691 \\
\hline Savings (\$/year) & 43,832 & 46,418 & 44,006 & 42,018 & 50,827 \\
\hline \% savings & $41.15 \%$ & $43.57 \%$ & $41.31 \%$ & $39.44 \%$ & $47.72 \%$ \\
\hline
\end{tabular}

Table 7. IEEE 119 system with reconfiguration only.

\begin{tabular}{ccccc}
\hline Items & $\begin{array}{c}\text { BPSOGSA } \\
\text { [30] (2018) }\end{array}$ & $\begin{array}{c}\text { SFS [42] } \\
\mathbf{( 2 0 2 0 )}\end{array}$ & FA [39] (2020) & $\begin{array}{c}\text { Proposed } \\
\text { Method }\end{array}$ \\
\hline Power losses $(\mathrm{kW})$ & 858.2 & 854.04 & 853 & 819.94 \\
\% reduction in power losses & $33.72 \%$ & $34.02 \%$ & $34.09 \%$ & $36.65 \%$ \\
$\mathrm{~V}_{\text {min }}$ (PU) & 0.932 & 0.9323 & 0.944 & 0.944 \\
Cost (\$) year) & 451,090 & 448,880 & 448,340 & 430,960 \\
Savings (\$/year) & 229,220 & 231,430 & 231,970 & 249,350 \\
\% savings & $33.69 \%$ & $34.02 \%$ & $34.09 \%$ & 36.652 \\
\hline
\end{tabular}

Table 8. IEEE 119 system with capacitor allocation only.

\begin{tabular}{ccccc}
\hline Items & $\begin{array}{c}\text { IHA-CSA } \\
{[13]}\end{array}$ & $\begin{array}{c}\text { IHA } \\
{[17]}\end{array}$ & $\begin{array}{c}\text { AEFA } \\
{[43]}\end{array}$ & $\begin{array}{c}\text { Proposed } \\
\text { Method }\end{array}$ \\
\hline Power losses $(\mathrm{kW})$ & 858.89 & 843.14 & 844.29 & 834.05 \\
\% reduction in power losses & $33.64 \%$ & $34.85 \%$ & $34.76 \%$ & $34.87 \%$ \\
V $_{\text {min }}(\mathrm{PU})$ & 0.906 & 0.902 & 0.906 & 0.9073 \\
Injected reactive power & 9000 & 9800 & 10,550 & 8850 \\
(KVAR) & & $497,737.50$ & 502,310 & $488,077.63$ \\
Cost (\$/year) & $501,392.60$ & $182,572.80$ & $177,570.90$ & $192,232.73$ \\
Savings (\$/year) & $178,917.80$ & $26.80 \%$ & $26.10 \%$ & $28.26 \%$ \\
\% savings & $26.30 \%$ & & & \\
\hline
\end{tabular}

The comparison in Tables 4-6 shows the effectiveness of the proposed method for three cases $(1,2$, and 3$)$ in terms of total power losses, minimum voltage, and energy-saving total power losses for case 1, case 2, and case 3 via the proposed algorithm was the lowest when compared to the other best previous algorithms. Moreover, the proposed method achieved a clear increase in the value of energy savings compared to the other methods, as evidenced by Figure 3. The IEEE 33 system with reconfiguration and optimal choice of capacitors via the MTS-HSSA algorithm provided the best energy saving compared with the other algorithms. On the other hand, it provided the lowest value of maximum voltage deviation. 
Table 9. IEEE 119 system with reconfiguration and capacitor allocation.

\begin{tabular}{cccc}
\hline Items & $\begin{array}{c}\text { MFPA [35] } \\
\mathbf{( 2 0 1 7 )}\end{array}$ & $\begin{array}{c}\text { MGABC [44] } \\
\mathbf{( 2 0 1 8 )}\end{array}$ & $\begin{array}{c}\text { Proposed } \\
\text { Method }\end{array}$ \\
\hline Power losses (kW) & 865.86 & 833.46 & 559.07 \\
\% reduction in power losses & $33.99 \%$ & $35.72 \%$ & $56.80 \%$ \\
V $_{\text {min }}$ (PU) & 0.93 & 0.9 & 0.96 \\
Injected reactive power & 7450 & 13,500 & 7400.9 \\
(KVAR) & 451,491 & 514,870 & 335,810 \\
Cost (\$/year) & 228,818 & 165,440 & 344,500 \\
Savings (\$/year) & $33.60 \%$ & $24.32 \%$ & $50.64 \%$ \\
\% savings & & &
\end{tabular}

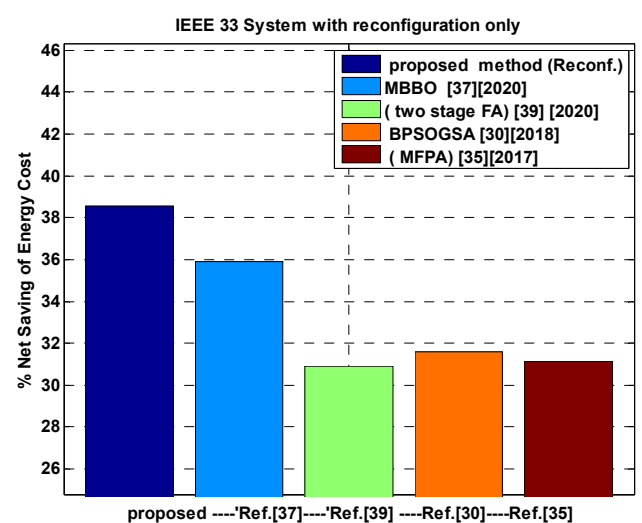

(a)

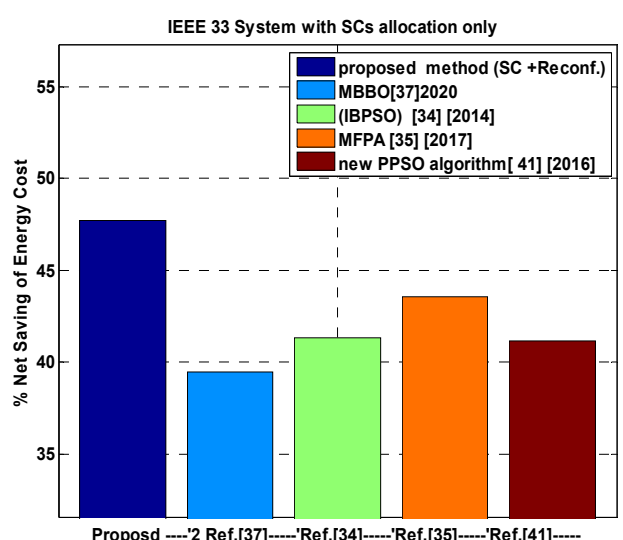

(c)

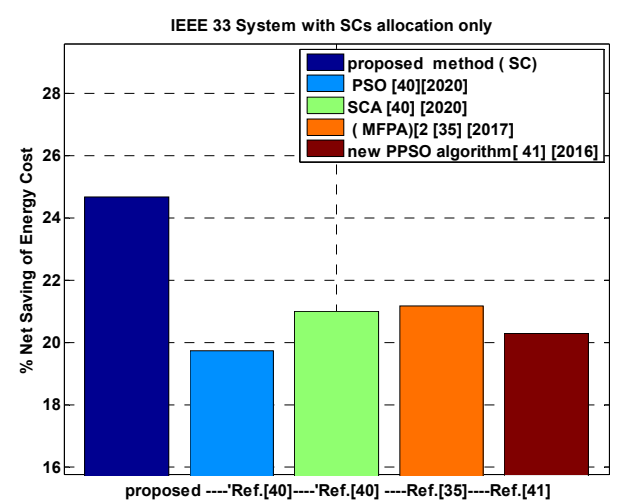

(b)

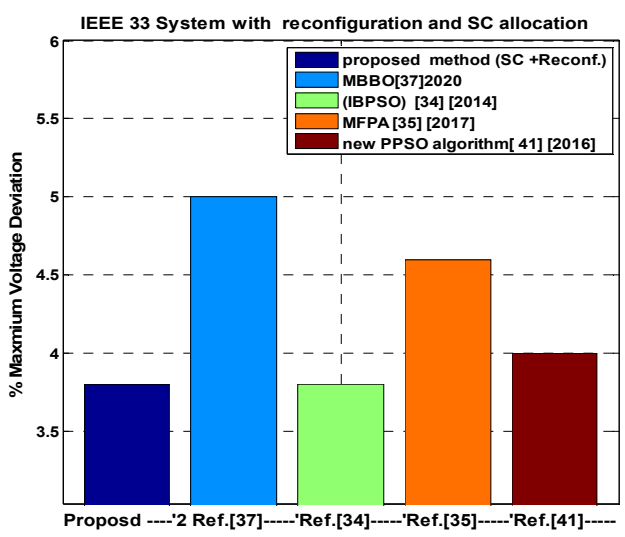

Figure 3. Comparison of the IEEE 33 system between the proposed algorithm and the best previous algorithms. (a) Energysaving \% with reconfiguration only; (b) energy-saving \% with shunt capacitor allocation only; (c) energy-saving \% with shunt capacitor allocation and reconfiguration; (d) maximum voltage deviation $\%$.

The main objective of this study was to maximize the energy saving of large power systems such as the IEEE 119 system, which consists of 133 switches; switches 1 to 118 are normally closed, and 119 to 133 are open. This system had a $V_{\text {nominal }}=11 \mathrm{kV}$ with the $\mathrm{V}_{\min }=0.9$ and $\mathrm{V}_{\max }=1.0$ The best open switches and optimal capacitor allocation for case 4, case 5, and case 6 to minimize the objective in Equation (1) are provided in Table 3. 
The performance of the distribution power system can be estimated by using the voltage deviation index [57], which is calculated by using Equation (16). The voltage stability index is used for monitoring the stability of the distribution power system and detecting the weak buses. It can be calculated by using Equation (17)

The voltage profile and the VSI profile were improved for the 119-bus at different cases via the proposed algorithm shown in Figure 4. Additionally, the maximum voltage deviation and the voltage deviation index were reduced. Power losses and energy costs were reduced for the three modified IEEE 119 systems (SC only, reconfiguration only, and SC with reconfiguration) via the proposed algorithm. It was observed that the performance of the IEEE 119 system with reconfiguration via the MTS-HSSA algorithm was better than its performance with the optimal choice of capacitors. Moreover, the IEEE 119 system with reconfiguration and optimal choice of capacitors via the MTS-HSSA algorithm provided the best performance compared with the other cases.

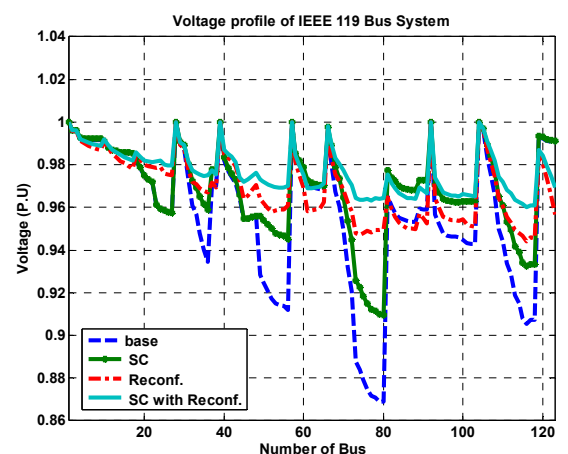

(a)

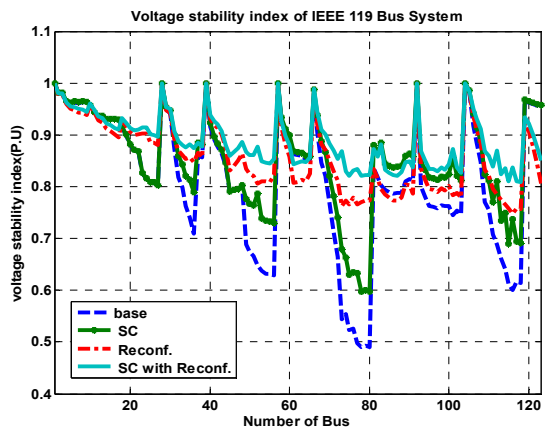

(c)

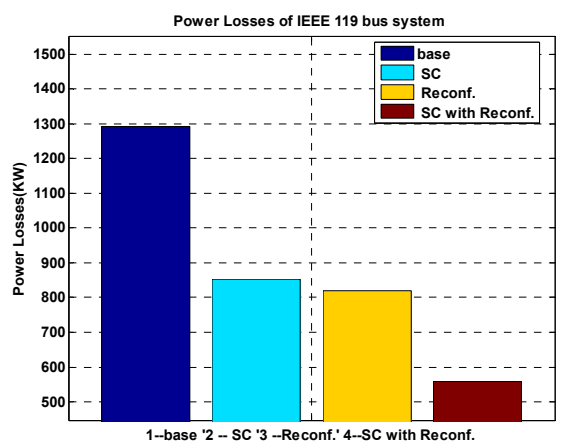

(e)

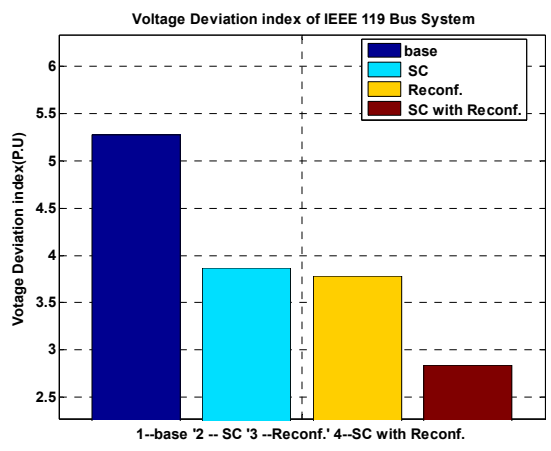

(b)

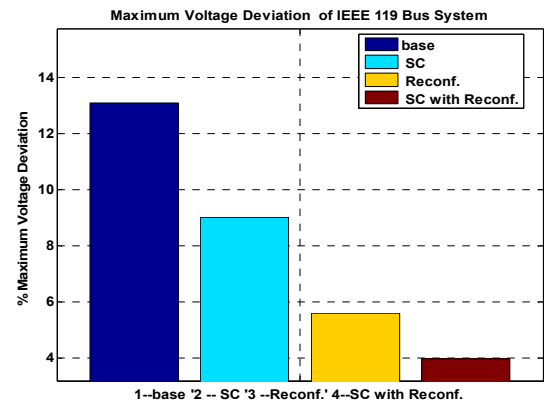

(d)

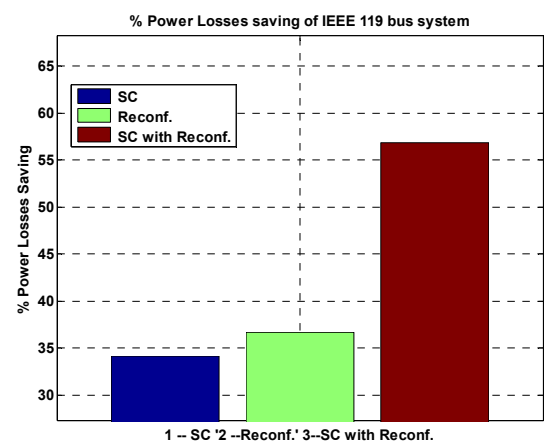

(f)

Figure 4. Performance of the 119-node test system with capacitor allocation only, the reconfiguration of the network only, and two approaches via the proposed algorithm: (a) Values of voltages at all buses; (b) values at different cases of the voltage deviation index; (c) values of voltage stability; (d) percentage of maximum voltage deviation; (e) power losses; (f) percentage power losses saving; (g) energy cost; (h) percentage of energy cost-saving. 
The comparison in Tables 7-9 shows the effectiveness of the proposed method for the three cases and is also shown in Figure 5. The proposed algorithm achieves energy-saving better than the best previous algorithms, especially in case 6 , as evidenced by Figure $5 c$. The IEEE 119 system with reconfiguration and optimal choice of capacitors via the MTSHSSA algorithm provided the best energy saving compared with the other algorithms. On the other hand, it provided the lowest value of maximum voltage deviation, as shown in Figure 5d. In this case, the percentage of energy-saving via the MTS-HSSA algorithm increased $33.649 \%$ more than the best one.

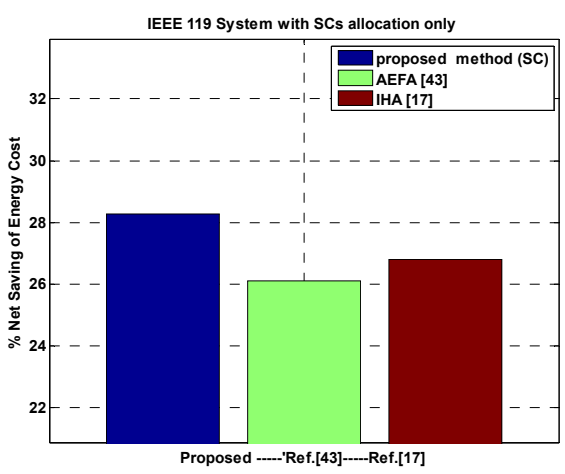

(a)

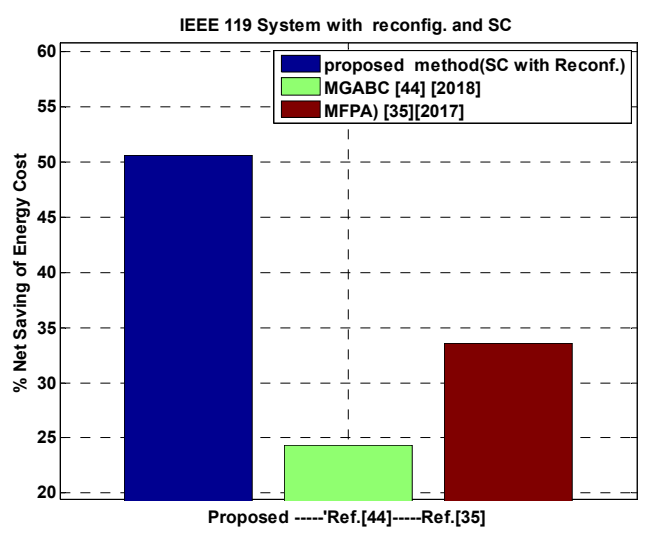

(c)

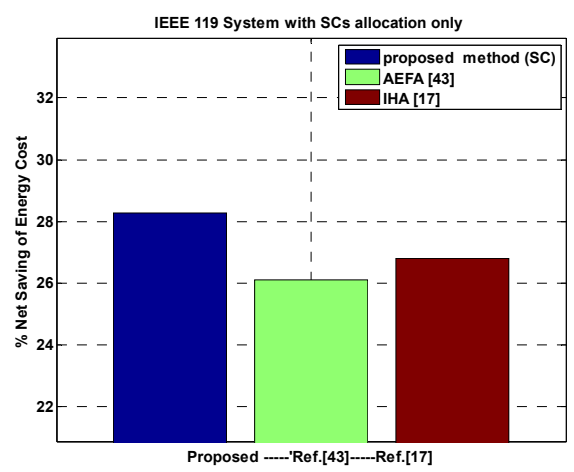

(b)

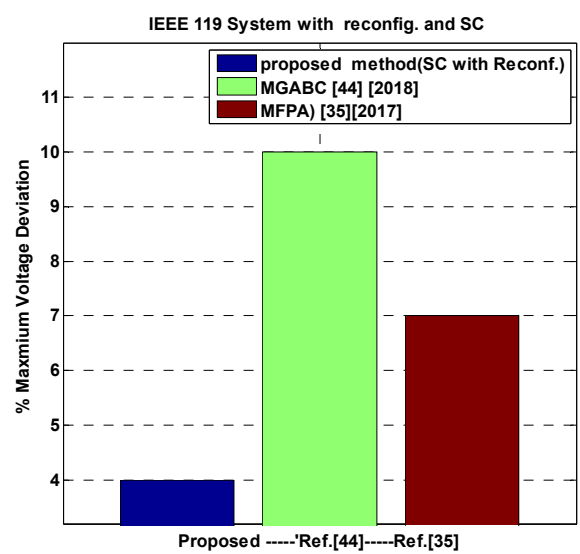

(d)

Figure 5. Comparison of the IEEE 119 system between the proposed algorithm and the best previous algorithms: (a) Energysaving \% with reconfiguration only; (b) energy-saving \% with shunt capacitor allocation only; (c) energy-saving \% with shunt capacitor allocation and reconfiguration; (d) maximum voltage deviation \%.

In Figures 6 and 7 an economic comparison was made between the proposed method and different strategies for energy saving, which included distributed generation. The cost calculations and data contained in [58] were used to calculate the energy saving for different methods. This data could be applied only to the specified case (the cost per KWh was $\$ 0.057$ ). It was clear that, in this case, the proposed method was the best out of all to save the cost of energy for each of the model IEEE 33 and IEEE 119 systems. The cost per Kwh was $\$ 0.035$ for another study case [59]. In this case, although the energy saving was better, the proposed method was the best out of all to save the cost of energy for each of the model IEEE 33 and IEEE 119 systems. Furthermore, it can also be extended for many maximization of energy saving strategies such as networks with soft open points and distributed generation [60]. The cost of distributed generation units has a wide range variation via the uncertainties of renewable energy source generation and energy 
demand [61,62]; it needs more study in the future to estimate general objective function to apply the proposed algorithm.

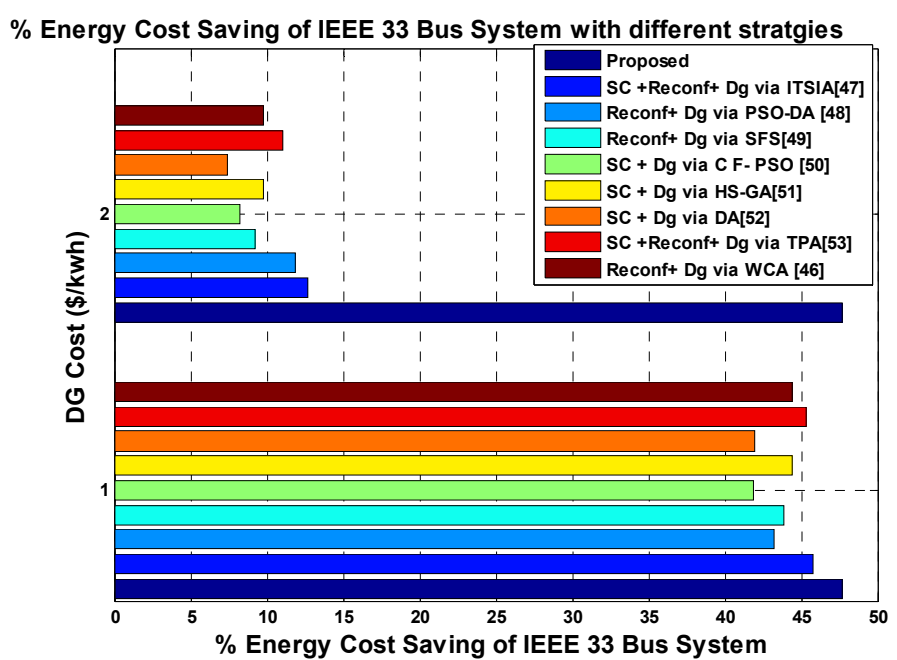

Figure 6. Comparison of \% energy savings for the IEEE 33 system with different strategies of energy saving.

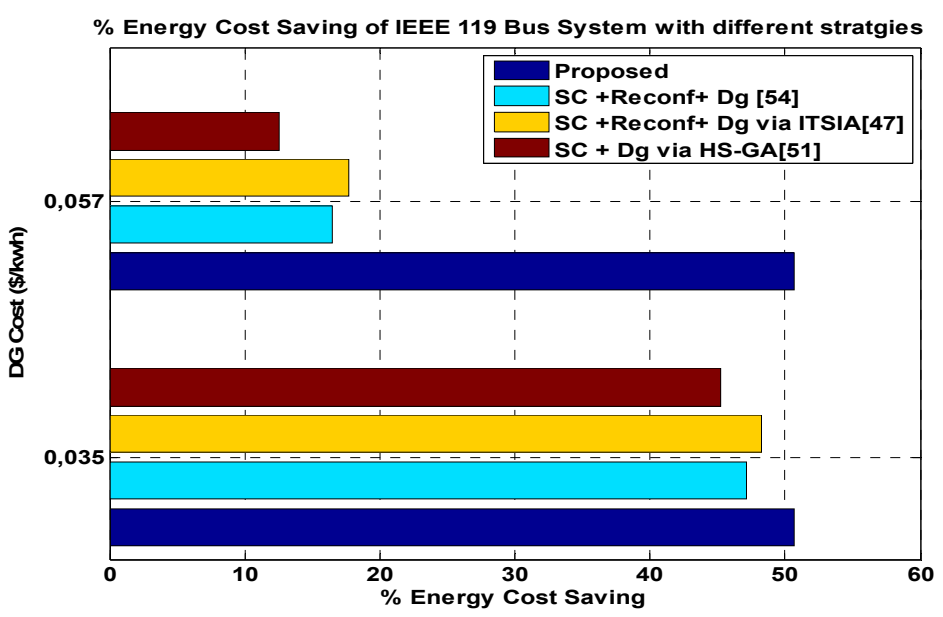

Figure 7. Comparison of \% energy saving for the IEEE 119 system with different strategies of energy saving.

The proposed route was applied to one of the unbalanced distribution power systems. This system was an IEEE 123 distribution power system, and its data is contained in [63] and its base data is tabulated in Table 10. The proposed route was also applied to the unbalanced distribution power systems influenced with DGs, which can be taken as a constant value and which were integrated at the weak buses according to a penetration level of $20 \%$, as presented in [45]. The results of the proposed mathematical analysis of the IEEE 123 distribution power system were placed in Table 11.

Table 10. The base data of the unbalanced IEEE 123 .

\begin{tabular}{cc}
\hline Items & IEEE 123 Base Values [45] \\
\hline Total losses $(\mathrm{kW})$ & 571.84 \\
\hline Minimum voltage & 0.86 \\
\hline Annual cost (\$/year) via Equation $(1)$ & 300,560 \\
\hline
\end{tabular}


Table 11. Output of the proposed method for the IEEE 123 system.

\begin{tabular}{cc}
\hline Items & Reconfiguration at Capacitor Location \\
\hline & 57350 \\
Location and size of capacitor (kW) (IEEE 123) & 34150 \\
without DG & 2250 \\
& 4850 \\
Location and size of capacitor (IEEE 123) & 8450 \\
without DG & 57260 \\
& 34150 \\
& 4850 \\
& 8350 \\
\hline Switches Reconfiguration without DG & 18135 close \\
& 150149 open \\
& 13152 close \\
60160 close \\
97197 close \\
5494 close \\
Switches reconfiguration with DG & 151300 close \\
25047 close \\
10562 open
\end{tabular}

The comparison in Table 12 shows the effectiveness of MTS-HSSA for the IEEE 123 unbalance system with and without DG integration in terms of total power losses, minimum voltage, and energy-saving. Total power losses via the proposed algorithm were the lowest, and the proposed method achieved a clear increase in the value of energy savings compared to the other methods, as evidenced by Figure 8. The IEEE 123 system with reconfiguration and optimal choice of capacitors via the MTS-HSSA algorithm provided the best energy saving out of all the algorithms. However, it provided the lowest value of maximum voltage deviation, and the voltage profile was improved for the 123-bus in different cases as shown in Figure 9.

Table 12. Unbalanced IEEE 123 system performance with different strategies.

\begin{tabular}{|c|c|c|c|c|}
\hline Items & $\begin{array}{c}\text { Pareto-Optim- } \\
\text { Based without } \\
\text { DG }[45]\end{array}$ & $\begin{array}{c}\text { Proposed } \\
\text { without DG }\end{array}$ & $\begin{array}{c}\text { Pareto-Optim- } \\
\text { Based with DG } \\
{[45]}\end{array}$ & $\begin{array}{c}\text { Proposed } \\
\text { with DG }\end{array}$ \\
\hline Power losses $(\mathrm{kW})$ & 260.11 & 79.5431 & 67.25 & 19.1 \\
\hline$\%$ reduction in power losses & $54 \%$ & $86.10 \%$ & $88 \%$ & $96 \%$ \\
\hline$V_{\min }(P U)$ & 0.94 & 0.969 & 0.97 & 0.98 \\
\hline Injected reactive power (KVAR) & $\longrightarrow$ & 2100 & - & 1650 \\
\hline Cost $(\$ /$ year $)$ & 136,710 & 56,028 & 35,347 & 20,681 \\
\hline Savings (\$/year) & 163,850 & 244,530 & 265,210 & 279,880 \\
\hline Savings (\$/year) & $54 \%$ & $86 \%$ & $88 \%$ & $93.20 \%$ \\
\hline
\end{tabular}




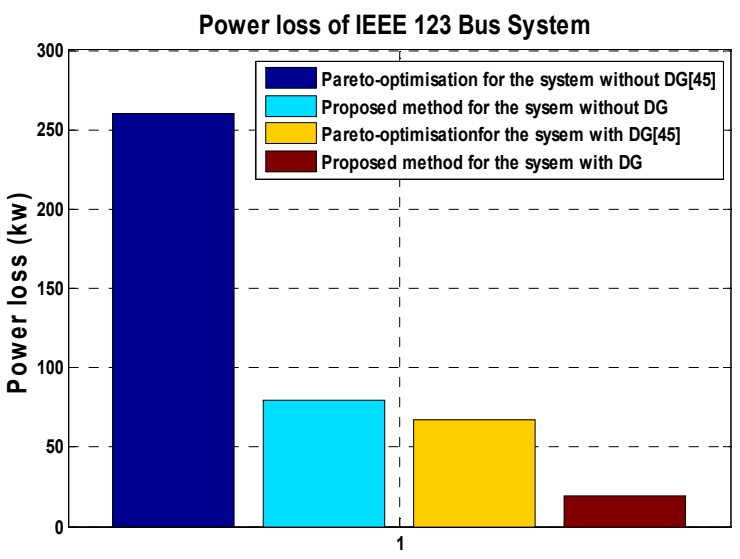

System without and with DG at different methods

(a)

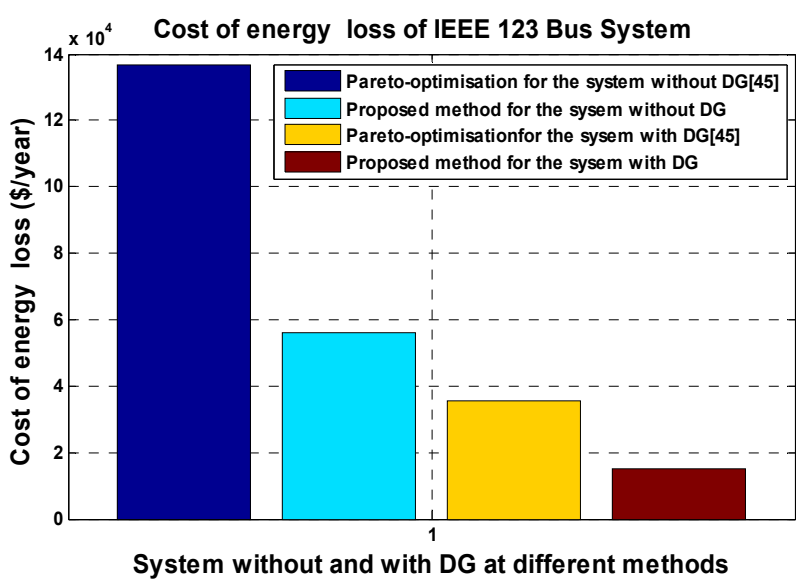

(b)

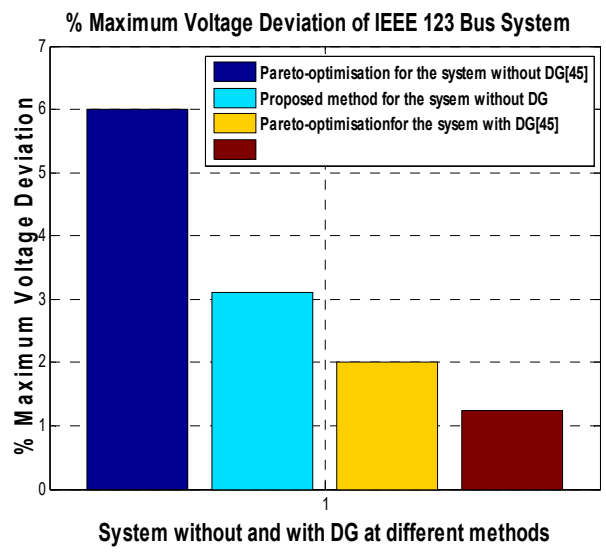

(c)

Figure 8. Comparison between the IEEE 123 unbalanced system using the proposed method and the best previous methods: (a) Power losses in kW; (b) Cost of energy losses savings in \$; (c) Maximum voltage deviation.

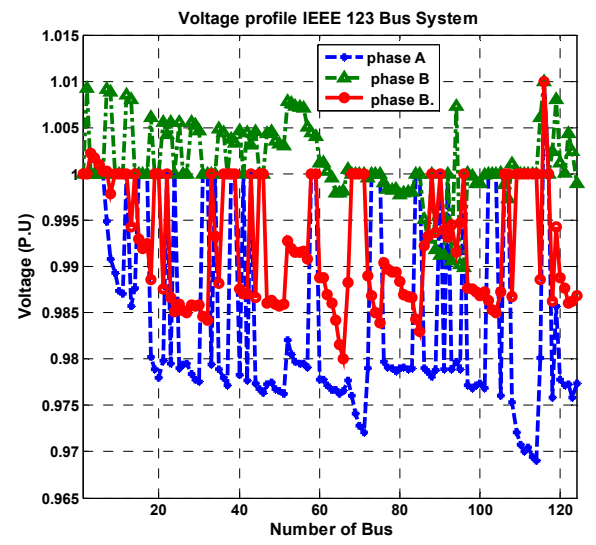

(a)

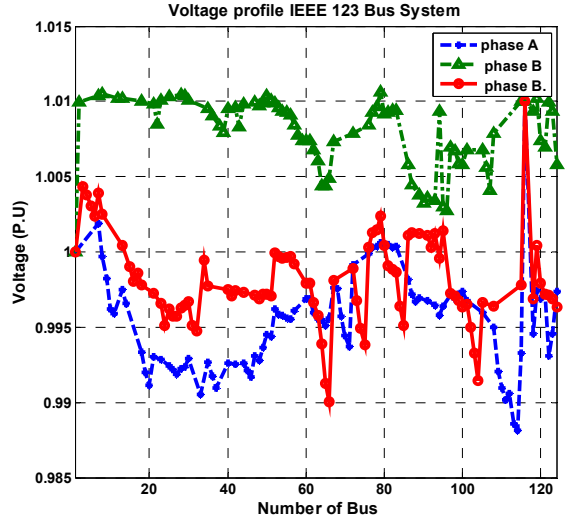

(b)

Figure 9. Voltage profile for three phases of the 123-node test unbalanced system: (a) Without DG via the proposed algorithm; (b) with DG via the proposed algorithm.

\section{Conclusions}

This study investigated a compound algorithm (MTS-HSSA) for reconfiguration and capacitor allocation of distribution power systems. The MTS-HSSA algorithm was explained in the previous section and has many advantages. The MTS-HSSA algorithm has a variable size of the reconfiguration problem for escaping from cycling and a local 
minimum. The MTS-HSSA algorithm restricts the trial solution by checking the system to be radial during the reconfiguration process. The results demonstrate that the proposed method is appropriate for energy saving and improving performance compared with other methods reported in the literature for IEEE 33-bus adopted systems, including large scale systems such as IEEE 119 and the IEEE 123 unbalanced distribution system. Moreover, the results demonstrate that the proposed method (the optimal choice of SC banks and the optimal reconfiguration via the proposed algorithm) is appropriate for energy saving compared with different strategies for energy saving, which included distributed generation (DG) at different levels of cost. In the proposed method, the power loss index was used to provide a good initial solution to the optimum allocation capacitor. The hyper-sphere space idea (HSC and its particle) in the proposed algorithm achieved the high convergence probability because of the space of searching was closely restricted.

From the comparison results, the following conclusions can be drawn: the effectiveness of the modified system in terms of low power losses (56.78\% reduction for the IEEE 119 bus) improved the voltage level (minimum voltage ( $0.9602 \mathrm{pu}$ for the IEEE $119 \mathrm{bus}$ ), and the modified system had the lowest annual cost of energy losses (50.64\% net saving for the IEEE 119 bus). For the IEEE 119 distribution system with reconfiguration and shunt capacitor allocation, the percentage of energy-saving via the MTS-HSSA algorithm increased 33.649\% more than the MFPA method. Additionally, the effectiveness of the modified system was demonstrated for unbalanced systems (IEEE 123) in terms of the reduction in power losses, the improvement in voltage level, and the reduction in annual cost of energy losses. For the IEEE 123 distribution system with reconfiguration and shunt capacitor allocation, the percentage of energy-saving via the MTS-HSSA algorithm increased about $70 \%$ more than the Pareto-optimization-based NR method.

Author Contributions: Conceptualization, M.A.-E.-H.M. and Z.M.A.; methodology, M.A.-E.-H.M. and Z.M.A.; software, M.A.-E.-H.M.; validation, M.A.-E.-H.M. and Z.M.A.; formal analysis, M.A.-E.H.M. and Z.M.A.; investigation, Z.M.A. and M.A.; resources, M.A.-E.-H.M.; data curation, M.A.-E.H.M., Z.M.A. and M.A; writing—original draft preparation, M.A. and S.F.A.-G.; writing-review and editing, M.A., Z.M.A. and M.A.; visualization, M.A. and Z.M.A.; supervision, M.A.-E.-H.M., Z.M.A., M.A. and S.F.A.-G.; project administration, M.A., Z.M.A. and S.F.A.-G.; funding acquisition, M.A. and S.F.A.-G. All authors have read and agreed to the published version of the manuscript.

Funding: This research was funded by Taif University Researchers Supporting Project Number (TURSP-2020/146), Taif University, Taif, Saudi Arabia and Deanship of Scientific Research at King Khalid University for funding this work through the Research Groups Program, under Grant number (RGP.1/255/42).

Institutional Review Board Statement: Not applicable for studies not involving humans or animals.

Informed Consent Statement: Not applicable.

Data Availability Statement: Not applicable.

Acknowledgments: The authors would like to acknowledge the financial support received from Taif University Researchers Supporting Project Number (TURSP-2020/146), Taif University, Taif, Saudi Arabia, The authors extend their appreciation to the Deanship of Scientific Research at King Khalid University for funding this work through the Research Groups Program, under Grant number (RGP.1/255/42).

Conflicts of Interest: The authors declare no conflict of interest.

\section{Appendix A Overview of the Tabu Search Algorithm}

To solve many engineering problems, the Tabu search is used. This algorithm has been used for solving the problem of shunt capacitor allocation [7]. The Tabu search algorithm has also been used for loss-minimization reconfiguration of large-scale distributed systems in [27] and [28]. The standard Tabu search algorithm is described by using the next flow chart, as shown in Figure A1. The standard algorithm is described as follows. 
Notation:

$s$ the current solution.

$s^{*}$ the best known solution.

$f^{*}$ the value of $s^{*}$.

$N(s)$ the neighood of $s$.

$N^{*}(s)$ the admissible subset of $\mathrm{N}(\mathrm{s})(\mathrm{non}-\mathrm{Tabu})$

Initialization:

All parameters of Tabu search [64] are initialized such as the Tabu list (empty), the candidate list (empty), the initial solution (created), the best solution (equal to the initial solution), and the cost function for the initial solution is calculated.

Choose an inial solution s0 set:

$s=s 0$

$f^{0}=f(s 0)$

$s^{*}=\mathrm{s}$

$\mathrm{T}=\varnothing$

Searching:

The cost function values are filtered by the Tabu move and aspiration criterion for all possible neighborhood solutions. Then, the Tabu list is updated.

While stopping criterion not satisfied do:

* select $\mathrm{s}$ in argmin $\left[f\left(s^{\prime}\right)\right] ; s^{\prime} \in$

$*$ if $f(s)<f^{*}$ then $f^{*}=f(s)$

$*$ record tabu for current move in $T$.

End while.

The above actions are repeated up to the maximum iteration number.

The modified TS algorithm is described in the following section. It has the variable size to escape from cycling and the local minimum.

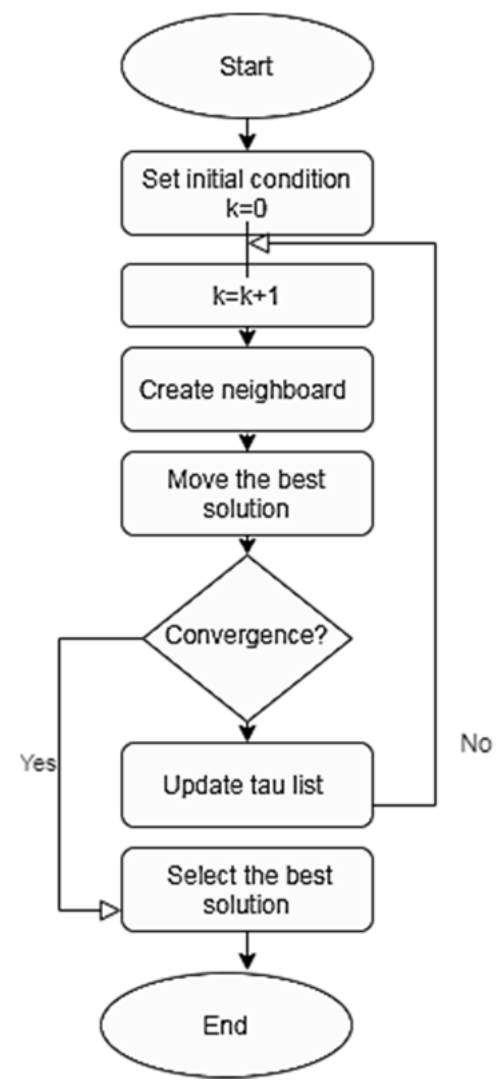

Figure A1. Tabu search flowchart. 


\section{Appendix B Overview of the Hyper-Spherical Search Algorithm}

The hyper-spherical search algorithm is investigated for the optimum solution to different problems [65], and it is used for the optimum choice of shunt capacitors in distribution power systems [18]. In this algorithm, the solutions are generated randomly in the specified band. For each solution (particle), and for each $\mathrm{N}$-dimensional problem, each particle is $1 \times \mathrm{N}$ vector, $\left(p_{1}, p_{2}, \ldots, p_{N}\right)$. The number of particles among hyper-spheres is distributed accordingly.

A better solution will be sought in spherical coordinates, and this is done by repositioning the particles. We found that the spherical coordinates of the solution change by changing both the radius and the angle in the predetermined framework. Each particle is represented by using spherical coordinates $(r, \theta$, and $\varphi)$, which are shown in Figure A2. Each point has $N-1$ angles in $N$-dimension space in spherical coordinates, as shown in Figure A2. Each point has two angles in three-dimensional space. The position of particles is changed via probability $P r_{\text {angle }}$ and $\mathrm{r} \in\left(r_{\min }, \mathrm{r}_{\max }\right)$ [65].

Figure A2 shows the searching region of the particle (dashed-space); the procedure of searching is achieved through moving in a $(\mathrm{r}, \theta, \varphi) . \theta$ and $\varphi$ varied uniformly between $(0,2 \pi)$, reproducing a new movement of the particle. These angles $(\theta$ and $\varphi)$ were varied with the probability $P r_{\text {angl }}$ for each iteration. After the total objective function was calculated for all particles, the SCs with the largest value of the objective function should be varied. The dummy particle [65] is shown in Figure A3. It should be allocated to a new SC via a set of objective functions (SOF). Dummy particles are selected to look for the new SC via the assignment probability of the SCs. Dummy particles that have the worst set objective function (SOF) (Figure A3) were selected to look for the new SC via the assignment probability. Then, the worst particles were eliminated, and new particles were generated until the best one was reached. The complete flow chart of the HASSA algorithm is shown in Figure A4.

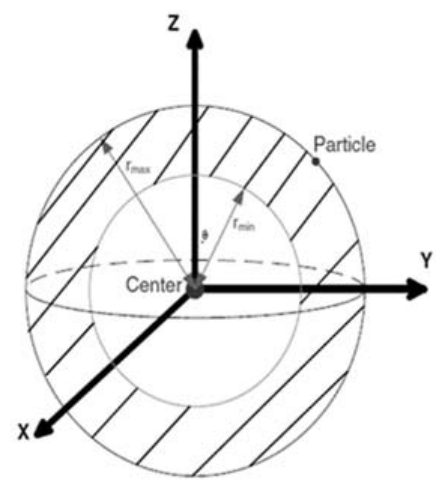

Figure A2. The searching region of the particle (dashed-space).

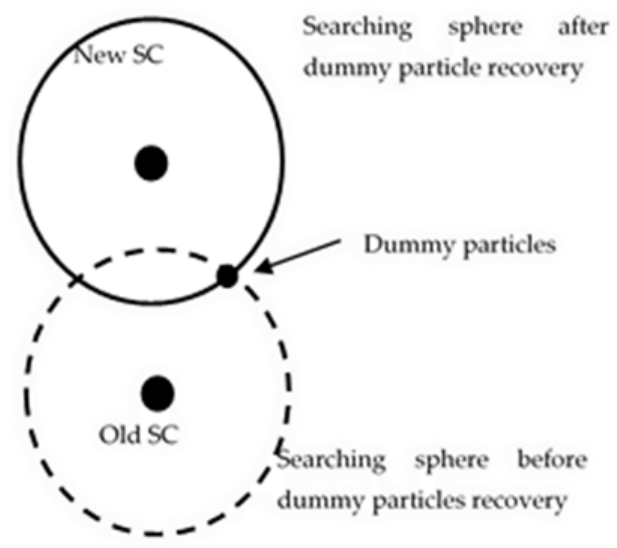

Figure A3. Dummy particle recovery. 


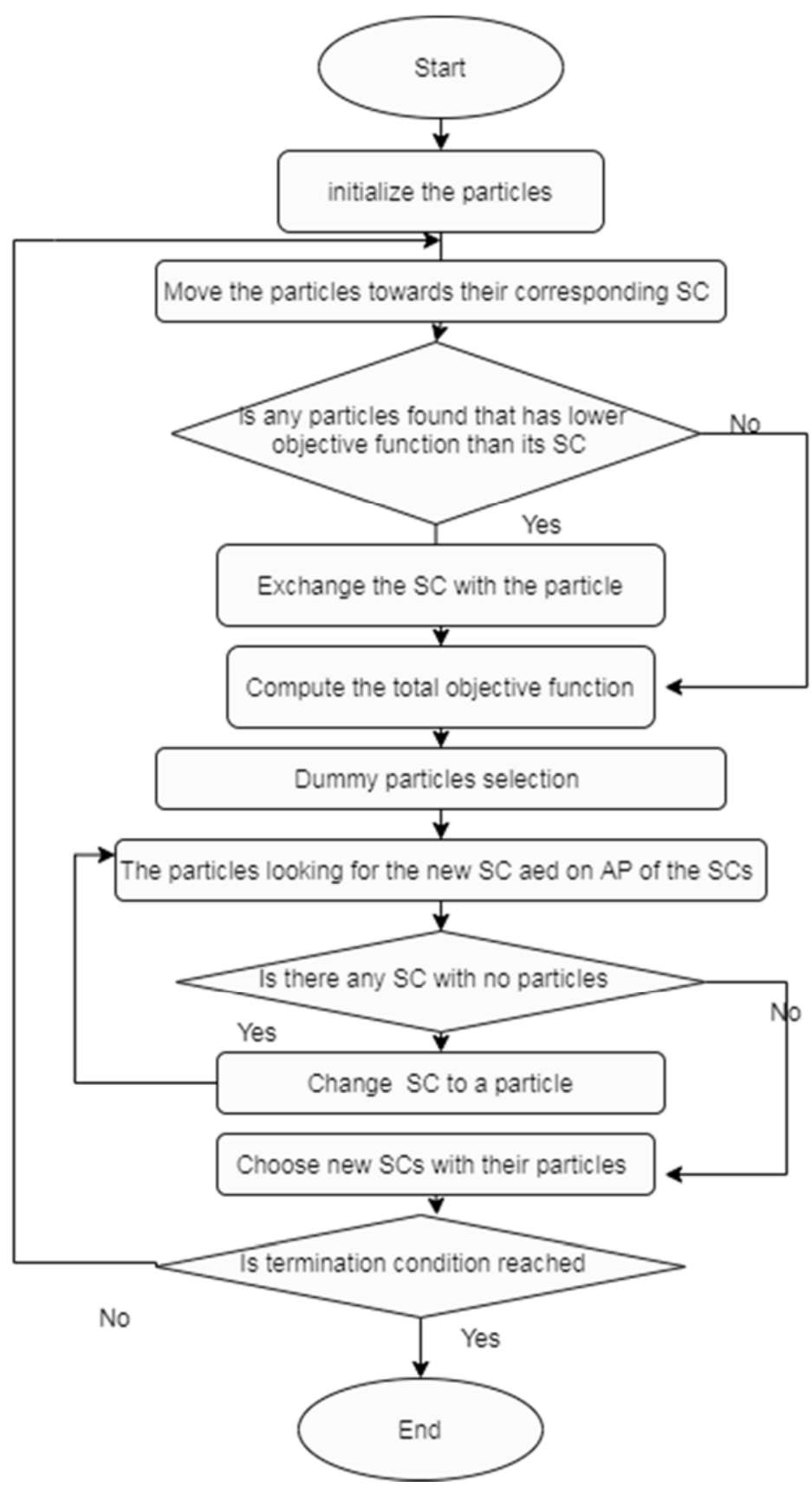

Figure A4. HSSA flow chart.

\section{References}

1. Gonen, T. Electric Power Distribution System Engineering, 2nd ed.; CRC Press: Boca Raton, FL, USA, 2008.

2. Georgilakis, P.S.; Hatziargyriou, N.D. A review of power distribution planning in the modern power systems era: Models, methods and future research. Electr. Power Syst. Res. 2015, 121, 89-100. [CrossRef]

3. Yuan, W.; Wang, J.; Qiu, F.; Chen, C.; Kang, C.; Zeng, B. Robust Optimization-Based Resilient Distribution Network Planning Against Natural Disasters. IEEE Trans. Smart Grid 2016, 7, 2817-2826. [CrossRef]

4. Grainger, J.J.; Lee, S.H. Optimum Size and Location of Shunt Capacitors for Reduction of Losses on Distribution Feeders. IEEE Trans. Power Appar. Syst. 1981, 100, 1105-1118. [CrossRef]

5. Cho, M.; Chen, Y. Fixed/switched type shunt capacitor planning of distribution systems by considering customer load patterns and simplified feeder model. IEE Proc. Gener. Transm. Distrib. 1997, 144, 533. [CrossRef]

6. Chiang, H.D.; Wang, J.C.; Cockings, O.; Shin, H.D. Optimal capacitor placements in distribution systems: Part1: A new formulation and the overall problem. IEEE Trans. Power Syst. 2007, 16, 630-637. [CrossRef] 
7. Gallego, R.A.; Moticelli, A.J.; Romero, R. Optimal capacitor placements in radial distribution networks using Tabu search. IEEE Trans. Power Syst. 2001, 16, 630-637. [CrossRef]

8. Sydulu, M.; Reddy, V. Index and GA based optimal allocation and sizing of distribution system capacitors. IEEE Power Eng. Soc. Meet. 2007, 1, 1-5.

9. Das, P.; Banerjee, S. Placement of capacitors for radial distribution systems using loss sensitivity factor and cuckoo search algorithm. Int. J. Sci. Res. Manag. 2013, 2, 751-757.

10. Devabalaji, K.R.; Yuvaraj, T.; Ravi, K. An efficient method for solving the optimal sitting and sizing problem of capacitor banks based on cuckoo search algorithm. Ain Shams Eng. J. 2018, 9, 589-597. [CrossRef]

11. Prakash, K.N.; Sydulu, M. Particle swarm optimization based capacitor placement on radial distribution system. IEEE Power Eng. Meet. 2007, 1, 1-5.

12. Alfergany, A.A.; Abdelaziz, A.Y. Artificial bee colony algorithm to allocate fixed and switched static shunt capacitors in radial distribution networks. Electr. Power Comp. Syst. 2014, 42, 427-438. [CrossRef]

13. Alfergany, A.A.; Abdelaziz, A.Y. Capacitor allocations in radial distribution networks using cuckoo search algorithm. IET Gener. Trans. Distrib. 2014, 8, 223-232. [CrossRef]

14. Su, C.T.; Chang, C.F.; Chiou, J.P. Optimal capacitor placement in radial distribution systems employing and colony search algorithm. Electr. Power Comp. Syst. 2005, 33, 931-946. [CrossRef]

15. Das, P.; Banerjee, S. Optimal sizing and placement of capacitor in a radial distribution system using loss sensitivity factor and firefly algorithm. Int. J. Eng. Comput. Sci. 2014, 3, 5346-5352.

16. Muthukumar, K.; Jayalalitha, S.; Ramasamy, M.; Haricharan, C. Optimal shunt capacitor allocation and sizing using harmony search algorithm for power loss minimization in radial distribution networks. Int. J. Develop. Res. 2014, 4, 537-545.

17. Ali, E.; Elazim, S.A.; Abdelaziz, A. Improved Harmony Algorithm and Power Loss Index for optimal locations and sizing of capacitors in radial distribution systems. Int. J. Electr. Power Energy Syst. 2016, 80, 252-263. [CrossRef]

18. Aboelyousr Farag, K.; Mohamed, M.A. Hyper-Spherical Search Algorithm for Optimal Sizing and Allocation of Capacitors in Radial Distribution Systems. J. Electr. Eng. 2018, 18, 1-8.

19. Civanlar, S.; Grainger, J.; Yin, H.; Lee, S. Distribution feeder reconfiguration for loss reduction. IEEE Trans. Power Deliv. 1988, 3 , 1217-1223. [CrossRef]

20. Fan, J.-Y.; Zhang, L.; McDonald, J. Distribution network reconfiguration: Single loop optimization. IEEE Trans. Power Syst. 1996, 11, 1643-1647. [CrossRef]

21. Kashem, M.; Ganapathy, V.; Jasmon, G. A geometrical approach for network reconfiguration based loss minimization in distribution systems. Int. J. Electr. Power Energy Syst. 2001, 23, 295-304. [CrossRef]

22. Chiang, H.D.; Jean-Jumeau, R.M. Optimal network reconfiguration distribution system. Part 1. Anew formulation and a solution methodology. IEEE Trans. Power Deliv. 1990, 5, 1902-1909. [CrossRef]

23. Jiang, D.; Baldick, R. Optimal electric distribution system switch reconfiguration and capacitor control. IEEE Trans. Power Syst. 1996, 11, 890-897. [CrossRef]

24. Jean, Y.J.; Kim, J.C. An efficient simulated annealing algorithm for network reconfiguration in large-scale distribution systems. IEEE Trans. Power Deliv. 2002, 17, 1070-1078. [CrossRef]

25. Ying, Y.H.; Saw, Y.H. Genetic algorithm based network reconfiguration for loss minimization in distribution systems. Power Eng. Soc. Gen. Meet. IEEE 2003, 1, 13-17.

26. Venkatesh, B.; Ranjan, R.; Gooi, H.B. Optimal Reconfiguration of Radial Distribution Systems to Maximize Loadability. IEEE Trans. Power Syst. 2004, 19, 260-266. [CrossRef]

27. Zhang, D.; Fu, Z.; Zhang, L. An improved TS algorithm for loss-minimum reconfiguration in large-scale distribution systems Electr. Power Syst. Res. 2007, 77, 685-694. [CrossRef]

28. Abdelaziz, A.; Mohammed, F.; Mekhamer, S.; Badr, M. Distribution Systems Reconfiguration using a modified particle swarm optimization algorithm. Electr. Power Syst. Res. 2009, 79, 1521-1530. [CrossRef]

29. Abdelaziz, A.; Mohamed, F.; Mekhamer, S.; Badr, M. Distri-bution system reconfiguration using a modified Tabu Search algorithm. Electr. Power Syst. Res. 2010, 80, 943-953. [CrossRef]

30. Fathy, A.; El-Arini, M.; El-Baksawy, O. An efficient methodology for optimal reconfiguration of electric distribution network considering reliability indices via binary particle swarm gravity search algorithm. Neural Comput. Appl. 2017, 30, 2843-2858. [CrossRef]

31. Ahmadian, A.; Elkamel, A.; Mazouz, A. An Improved Hybrid Particle Swarm Optimization and Tabu Search Algorithm for Expansion Planning of Large Dimension Electric Distribution Network. Energies 2019, 12, 3052. [CrossRef]

32. Farahani, V.; Vahidi, B.; Abyaneh, H.A. Reconfiguration and capacitor placement simultaneously for energy loss reduction based on an improved reconfiguration method. IEEE Trans. Power Syst. 2012, 27, 587-595. [CrossRef]

33. Rao, R.S. An hybrid approach for loss reduction in distribution systems using harmony search algorithm. Int. J. Electr. Electron. Eng. 2010, 4, 461-467.

34. Sedighizadeh, M.; Dakhem, M.; Sarvi, M.; Kordkheili, H.H. Optimal reconfiguration and capacitor placement for power loss reduction of distribution system using improved binary particle swarm optimization. Int. J. Energy Environ. Eng. 2014, 5, 1-11. [CrossRef] 
35. Namachivayam, G.; Sankaralingam, C.; Perumal, S.K.; Devanathan, S.T. Reconfiguration and Capacitor Placement of Radial Distribution Systems by Modified Flower Pollination Algorithm. Electr. Power Components Syst. 2016, 44, 1492-1502. [CrossRef]

36. Mostafa, S.; Bakhtiary, R. Optimal multi-objective reconfiguration and capacitor placement of distribution systems with the Hybrid Big Bang-Big Crunch algorithm in the fuzzy framework. Ain Shams Eng. J. 2016, 7, 113-129.

37. Fathi, K.H.; Hussain, A.N.; Al-Jubori, W.K.S. Dual technique of reconfiguration and capacitor placement for distribution system. Int. J. Electr. Comput. Eng. 2020, 10, 2088-8708.

38. Yodphet, D.; Onlam, A.; Siritaratiwat, A.; Khunkitti, P. Electrical distribution system reconfiguration for power loss reduction by the Salp Swarm algorithm. Int. J. Smart Grid Clean Energy 2019, 8, 156-163. [CrossRef]

39. Al Samman, M.; Mokhlis, H.; Mansor, N.N.; Mohamad, H.; Suyono, H.; Sapari, N.M. Fast Optimal Network Reconfiguration With Guided Initialization Based on a Simplified Network Approach. IEEE Access 2020, 8, 11948-11963. [CrossRef]

40. Rizk-Allah, R.M.; Hassanien, A.E.; Oliva, D. An enhanced sitting-sizing scheme for shunt capacitors in radial distribution systems using improved atom search optimization. Neural Comput. Appl. 2020, 32, 1-29. [CrossRef]

41. Sayadi, F.; Esmaeili, S.; Keynia, F. Feeder reconfiguration and capacitor allocation in the presence of non-linear loads using new P-PSO algorithm. IET Gener. Transm. Distrib. 2016, 10, 2316-2326. [CrossRef]

42. Vo Ngoc, D.; Tran Anh, N. Distribution Network Reconfiguration for Power Loss Reduction and Voltage Profile Improvement Using Chaotic Stochastic Fractal Search Algorithm. Complexity. 2020. Available online: https://www.sciencedirect.com/science/ article/pii/S2090447919301248 (accessed on 27 May 2021).

43. Abdelsalam, A.A.; Hossam, A.G. Shunt Capacitors Optimal Placement in Distribution Networks Using Artificial Electric Field Algorithm. In Proceedings of the 2019 IEEE 7th International Conference on Smart Energy Grid Engineering (SEGE), Oshawa, ON, Canada, 12-14 August 2019; pp. 77-85. [CrossRef]

44. Mukul, D.; Kundu, P.; Jariwala, H.R. Optimal integration of shunt capacitor banks in distribution networks for assessment of techno-economic asset. Comput. Electr. Eng. 2018, 71, 331-345.

45. Gangwar, P.; Singh, S.N.; Chakrabarti, S. Network reconfiguration for the DG-integrated unbalanced distribution system. IET Gener. Transm. Distrib. 2019, 13, 3896-3909. [CrossRef]

46. Esmaeilian, H.R.; Fadaeinedjad, R. Energy Loss Minimization in Distribution Systems Utilizing an Enhanced Reconfiguration Method Integrating Distributed Generation. IEEE Syst. J. 2015, 9, 1430-1439. [CrossRef]

47. Muhammad, M.A.; Mokhlis, H.; Naidu, K.; Amin, A.; Franco, J.F.; Othman, M. Distribution Network Planning Enhancement via Network Reconfiguration and DG Integration Using Dataset Approach and Water Cycle Algorithm. J. Mod. Power Syst. Clean Energy 2020, 8, 86-93. [CrossRef]

48. Rafi, V.; Dhal, P.K. Maximization savings in distribution networks with optimal location of type-I distributed generator along with reconfiguration using PSO-DA optimization techniques. Mater. Today Proc. 2020, 33, 4094-4100. [CrossRef]

49. Tran, T.T.; Truong, K.H.; Vo, D.N. Stochastic fractal search algorithm for reconfiguration of distribution networks with distributed generations. Ain Shams Eng. J. 2020, 11, 389-407. [CrossRef]

50. Balu, K.; Mukherjee, V. Siting and Sizing of Distributed Generation and Shunt Capacitor Banks in Radial Distribution System Using Constriction Factor Particle Swarm Optimization. Electr. Power Compon. Syst. 2020, 48, 697-710. [CrossRef]

51. Almabsout, E.A.; El-Sehiemy, R.A.; An, O.N.U.; Bayat, O. A Hybrid Local Search-Genetic Algorithm for Simultaneous Placement of DG Units and Shunt Capacitors in Radial Distribution Systems. IEEE Access 2020, 8, 54465-54481. [CrossRef]

52. Suresh, M.C.V.; Belwin, E.J. Optimal DG placement for benefit maximization in distribution networks by using Dragonfly algorithm. Renew. Wind. Water Sol. 2018, 5, 4. [CrossRef]

53. Tolabi, H.B.; Ara, A.L.; Hosseini, R. A new thief and police algorithm and its application in simultaneous reconfiguration with optimal allocation of capacitor and distributed generation units. Energy 2020, 203, 11791. [CrossRef]

54. Muthukumar, K.; Jayalalitha, S. Integrated approach of network reconfiguration with distributed generation and shunt capacitors placement for power loss minimization in radial distribution networks. Appl. Soft Comput. 2017, 52, 1262-1284.

55. Sadeghian, O.; Oshnoei, A.; Kheradmandi, M.; Khezri, R.; Mohammadi-Ivatloo, B. A robust data clustering method for probabilistic load flow in wind integrated radial distribution networks. Int. J. Electr. Power Energy Syst. 2020, 115, 105392 [CrossRef]

56. Helmi, A.M.; Carli, R.; Dotoli, M.; Ramadan, H.S. Efficient and Sustainable Reconfiguration of Distribution Networks via Metaheuristic Optimization. IEEE Trans. Autom. Sci. Eng. 2021. [CrossRef]

57. Fetouh, T.; Elsayed, A.M. Optimal Control and Operation of Fully Automated Distribution Networks Using Improved Tunicate Swarm Intelligent Algorithm. IEEE Access 2020, 8, 129689-129708. [CrossRef]

58. Elsayed Abdallah, M.; Mishref, M.M.; Farrag, S.M. Distribution system performance enhancement (Egyptian distribution system real case study). Int. Trans. Electr. Energy Syst. 2018, 28, e2545. [CrossRef]

59. Talavera, D.; Pérez-Higueras, P.; Ruíz-Arias, J.; Fernández, E. Levelised cost of electricity in high concentrated photovoltaic grid connected systems: Spatial analysis of Spain. Appl. Energy 2015, 151, 49-59. [CrossRef]

60. Diaaeldin, I.; Abdel Aleem, S.; El-Rafei, A.; Abdelaziz, A.; Zobaa, A.F. Optimal network reconfiguration in active distribution networks with soft open points and distributed generation. Energies 2019, 12, 4172. [CrossRef]

61. Melhem, F.Y.; Grunder, O.; Hammoudan, Z.; Moubayed, N. Energy management in electrical smart grid environment using robust optimization algorithm. IEEE Trans. Ind. Appl. 2018, 54, 2714-2726. [CrossRef] 
62. Mohsen, H.S.; Carli, R.; Dotoli, M. Robust optimal energy management of a residential microgrid under uncertainties on demand and renewable power generation. IEEE Trans. Autom. Sci. Eng. 2020, 18, 618-637.

63. Feeders, D.T. IEEE PES Distribution System Analysis Subcommittee. 2011. Available online: http://sites.ieee.org/pes-testfeeders/ (accessed on 27 May 2021).

64. Gendreau, M. An introduction to tabu search. In Handbook of Metaheuristics; Springer: Boston, MA, USA, 2003 ; pp. 37-54.

65. Karimi, H.; Sanjari, M.J.; Gharehpetian, G.B. Hyper-spherical search (HSS) algorithm: A novel meta-heuristic algorithm to otimize nonlinear functions. Neural Comp. Appl. 2014, 25, 1455-1465. [CrossRef] 